\title{
A Dialogue with Dr Mohammad Rostami Nejad
}

\author{
Peter Makovicky* \\ Co-editor, International Journal of Celiac Disease, Newark, United States \\ *Corresponding author: pmakovicky@email.cz
}

\begin{abstract}
We are continuing to journal interview and today Dr Mohammad Rostami Nejad from Gastroenterology and Liver Diseases Research Center of Shahid Beheshti University of Medical Sciences, Tehran, Iran is asked.
\end{abstract}

Keywords: interview, journal questions, a great personality

Cite This Article: Peter Makovicky, "A Dialogue with Dr Mohammad Rostami Nejad." International Journal of Celiac Disease, vol. 5, no. 2 (2017): 83-85. doi: 10.12691/ijcd-5-2-2.

\section{Could You Introduce Yourself to the Readers? When/where Were You Born? Where Did You Attend School and University? Where Did You Obtain Specialty Training, Particularly in Gastroenterology and Liver Diseases?}

I was born in Aleshtar (Lorestan Province), Iran, on 23 September 1979 and passed my secondary school exam in 1997 at the Emam Ali high school in Aleshtar Lorestan. My AS degree was Veterinary and took place at the Azad University, Shahrekord branch, Iran from 1998-2000. After that I started My BS degree on laboratory of veterinary medicine in the period 2003 until 2005 at the Azad University, Research and Science branch Tehran.

Since April 2005 I have been working as research fellow at the Research Institute for Gastroenterology and Liver Diseases (RIGLD), Shahid Behehsti University of Medical Sciences, Tehran. At the same time I have got my MSc degree on Medical Parasitology.

Since April 2009 I was assigned to the objectives of my $\mathrm{PhD}$ project under supervision of Dr. Kamran Rostami, Prof. Mohammad Reza Zali and Prof. Chris Mulder and have graduated in December 2012 in The Netherlands. Also I have received my second $\mathrm{PhD}$ on BioMedicine in Shahid Beheshti University of Medical Sciences in March 2014.

I have scientific collaboration with different national and international centers and universities, performed more than 60 projects and published 130 papers, 2 books on basic nutrition and diagnosis of celiac disease in Persian in 2009 and 2010 respectively, 2 book chapters in English, book on Protozoology in 2015, 2 guide books for patients and specialists for celiac disease 2017, and also my new book on Celiac and non-celiac gluten sensitivity is under writing.

I also estabilished the first celiac diseases website in Persian (www.celiac.ir)

\section{Where Are You Currently Work and on What Position? Some Information about Daily Routine Job Description?}

Currently I am head of coeliac disease department at RIGLD and the Internal Editor of Gastroenterology and Hepatology From Bed to Bench (GHFBB) journal. I have 20 postgraduate students incuding immunologists, genetics, cellular and mulecular, bacteriologist, medical education, internists, residents and GI assistances which who are busy with their thesis regarding celiac disease and non-celiac gluten sensitivity.

\section{What Was Your Daily Routine Job Description and What Was Your Clinical and Research Focus in Gastroenterology?}

I am working 6 days a week from 7.30 am till 6:00 pm. In addition to research activities, I am research consultant of RIGLD and therefore responsible to all aspects of Gastrointestinal and Liver Diseases researches there. My research focus is gluten related disorders especially celiac disease and non-celiac gluten sensitivity especially pathogenesis, signalling pathways, Immunology, management and also their association with other GI disorders like IBD and IBS.

\section{What and Who Stimulated Your Interest in Celiac Disease?}

In 2007 when I have been working as research fellow at the Research Institute for Gastroenterology and Liver Diseases (RIGLD) my big brother Dr.Kamran Rostami who is gastroenterologist and got $\mathrm{PhD}$ on celiac disease in 1998 and expert on celiac disease encouraged me to do 
some reseaches on celiac disease in Iran. In that time few studies were performed in the whole country and we did not have clear vision of disease. In that time I would like to know more about celiac disease. When I came to the celiac research, a 27-year-old female was admitted to our hospital with typical presentstion of celiac disease. after serology and pathology screening, her celiac disease was confirmed and using GFD all her sign and symptoms were improved after 3 months. After that I really interested in knowing more about celiac disease and therefore completely changed my research filed to celiac disease.

\section{What is the Awareness of Celiac Disease in Iran and Generally in Other Middle East Countries?}

Fortunately different studies were carried out in our department and based on our published data the government, general population and physicians have got the importance of early diagnosis and treatment of celiac disease. During the last year we held different educational meetings in different parts of the country for patients and physicians and we received a very positive feedbacks. I think between Middle East countries Iran, Turkey and little bit India has great awareness of celiac disease. But we are at the beginning of the way.

\section{Are there Some Differences Comparing Europe, US, Canada?}

Until a few years ago, it was thought that gluten intolerance exclusively affecting European origin and they described typical features of celiac patients. Also until a decade ago, $\mathrm{CD}$ was considered to be very rare in Middle Eastern countries due to lack of sufficient studies. A comparison of studies in European and Middle Eastern countries has shown that $\mathrm{CD}$ is common in both areas, with an almost similar prevalence. A marked increase in $\mathrm{CD}$ prevalence and incidence in Middle Eastern countries similar to Europe and US is because of the availability of new, simple, very sensitive and specific serological tests, therefore do some relaible research can be at least partially explained a high degree of disease suspicion.

\section{What Are the Options for Patients with Celiac Disease in Iran? Here, We Are Thinking about Gluten Free Diet, Gluten Free Foods and Possibly Other Conveniences?}

As you may know that cultivation of wheat and barley, first exploited and intensively developed in Levant and western Zagros (Iran), slowly spread to other countires. Therefore, high wheat consumption has been a major component of the Iranian diet for thousands of years. The current wheat consumption per capita per year in Iran shows Iranians rank as one of the top wheat-consuming populations in the Asia-Pacific region with a per capita consumption of up to $150 \mathrm{~kg} /$ year. We in accordance to the guidlines recommnded the GFD for all confirmed celiac patients. Meanwhile, wheat elimination of Iranian diet is so difficult. On the other hands since commercial gluten-free products are not easily available and significantly more expensive than their gluten-containing products in this area, therefore inaddition to limited import GFD products, some national companies emplied to porduce some GFD products for Iranian patients but as I said before, "we are at the beginning of the way".

\section{In Europe, We Have Less or More Problems with Low Diagnosis and Especially Diagnosis of Atypical Celiac Disease. Is the Situation in Iran Similar? Is There Some Specific Celiac Research?}

As you mentioned this is general problem in the whole world, not only in Europe. According to the published data, for each diagnosed patients there is 78 undiagnosed or misdiagnosed in Iran and this may due to lack of specialists' knowledge. Regarding the second part of your question, our publication in 2009 in J Gastrointestin Liv Dis showed that screening of patients with non-specific GI symptoms running a greater risk of $\mathrm{CD}$, e.g., some with dyspepsia. Also in our other study the investigation of celiac disease in patients with dyspepsia showed that the prevalence of $\mathrm{CD}$ among dyspeptic individuals is significantly $(2.5 \%)$ higher than in the general population $(1 \%)$ in Iran. It seems that it is better to focus on nonspecific specificities of the CD spectrum when the healthrelated life quality of coeliac patients with atypical presentation is impaired.

\section{What Was the Most Progressive and Most Important Moment in the Research of Celiac Disease?}

The availability of new, simple, very sensitive and specific serological tests (DGP, AGA, AEM and tTGA) in addition to expert pathologists and gastroenterologists with increase awarnesses are the most important moment in the research of celiac disease. But we should still keep waiting and see what happen in the future.

\section{Readers Know that You Are Working in the Research. So would You be so Kind and can You Tell Your Opinion about Current and Future All World Research of Celiac Disease?}

There is challenge in the management of celiac disease. I am currently participated to write the recent international guideline in celiac disease, but diagnostic approaches that we discussed are not applicable in all parts of the world as 
some diagnostic tools like HLA typing is not available or if available is so expensive. In countries like Iran it is too difficult to prescribe a GFD because as I said above Iran is one of the top wheat-consuming populations in the AsiaPacific region. Therefore in developing counteries in addition to celiac disease managment difficulties, we have GFD challenging. Lack of physician and general population's awareness of onset of symptoms, diagnosis and treatment may contribute to the underdiagnosis of celiac disease. The results of our recent study indicate that increase awareness in the general practitioners as well as general population is necessary to prevent the complications due to late diagnosis or underdiagnosis of celiac disease. Finally I would suggest that we more focus on increase awareness by education for different groups. On the other hands clinical trials are at the first phase and their results may change the future of research of celiac disease but I hope we can produce the gluten free wheat, established a non-invasive diagnostic tools, develop a vaccine and/or safe drugs in the near future.

\section{Do You Think that Celiac Disease will One Day be Fully Curable and a Gluten-free Diet will not be Required?}

It is very difficult to say YES. Various groups in different parts of the world are focused on specific targets which are involved in the pathogenesis of celiac disease. At the moment and as I said above clinical trials are at the first phase and their results may contribute to change the future of celiac disease. Developing of vaccine for celiac disease is one of the important ongoing research that I hope patients can use it for their disease cure instead of GFD for whole time.

\section{Do You Have Some Massage to the Journal Readers and Journal Contributors?}

When the journal was established, Prof. Samasca invited me to be part of the editorial board of International journal of Celiac Disease, I rapidly accept his invitation. Because I knew that we need a specific journal to distribute the findings of celiac disease researches worldwide. I would like to express my congratulation to Editor In Chief and others in Journal officers who provided this multidisciplinary journal. This promise will be given to readers, the many dark spots of celiac disease' pathogenesis will be determined by conducting extensive researches and good news are in the way. 